\title{
Drug-resistant vasospastic angina pectoris with plaque erosion in the focal spastic lesion confirmed with coronary angioscopy
}

\author{
Masahiro Koen, Shunichi Nakamura, Hitoshi Takano, Wataru Shimizu
}

Department of Cardiovascular Medicine, Nippon Medical School, Tokyo, Japan

\section{Correspondence to} Dr Shunichi Nakamura, s-nakamura@nms.ac.jp

Accepted 8 May 2015

\section{CrossMark}

\footnotetext{
To cite: Koen $\mathrm{M}$, Nakamura S, Takano $\mathrm{H}$, et al. BMJ Case Rep Published online: [please include Day Month Year] doi:10.1136/bcr-2015209648
}

\section{DESCRIPTION}

Plaque erosion within the coronary artery accounts for up to $20 \%$ of all sudden deaths and up to $40 \%$ of sudden deaths as a result of coronary thrombi in patients with coronary artery atherosclerosis. ${ }^{1}{ }^{2}$ We present a case of drug-resistant vasospastic angina pectoris (VSA) with erosion in the focal spastic lesion confirmed with coronary angioscopy (figure 1). A 78-year-old man presented to the coronary care unit with sudden chest pain accompanied by ECG ST segment elevation on V1-V3 and elevation of serum troponin-T level. A coronary angiography (CAG) revealed $90 \%$ stenosis in segment 2 of the right coronary artery, and this was removed by an intra-arterial injection of nitroglycerin. The left coronary artery was normal. Based on the above findings, acute coronary syndrome (ACS) associated with VSA was diagnosed. One month later, the patient was readmitted for ACS. CAG showed no stenosis, and an acetylcholine provocation test was performed in conjunction with adequate medication therapy (videos 1 and 2). As a result, focal vasospasm was induced, with the patient experiencing chest pain and an ECG change at segment 2 (figure 2). Coronary angioscopy showed yellow plaque with erosion at segment 2, similar to that of ACS (video 3 and figure 3). Percutaneous coronary intervention (PCI) was performed in this segment using a bare metal stent in conjunction with drug therapy. The PCI was successful, and the patient no longer experienced chest pain or ACS recurrence.

This is the first case in which intimal injury of a focal spastic lesion has been confirmed by coronary angioscopy in a case of ACS. Pathological intimal injury has been previously observed in VSA, ${ }^{1}$ and a causal relationship has been reported between intimal injuries (such as haemorrhage, flap, thrombusor ulcer) and VSA. These factors have not been previously reported in the context of ACS. PCI is a controversial method of treatment for VSA. While some case reports have shown the therapeutic validity of stent placement for drug-resistant focal VSA, ${ }^{3}$ other reports have described provocation of vasospasm at the stent edge following this procedure. The influence of the stent in these cases-particularly the drug-eluting stent-was unclear. In this case, while the coronary artery stenosis was treated, we chose to supplement this treatment with PCI with a bare metal stent. As a result of this treatment, the VSA did not recur and was not provoked by follow-up acetylcholine stress testing after PCI.

In conclusion, the case presented here elucidates the mechanism underlying intractable focal drugresistant VSA and provides evidence of a possible therapy for this condition. 


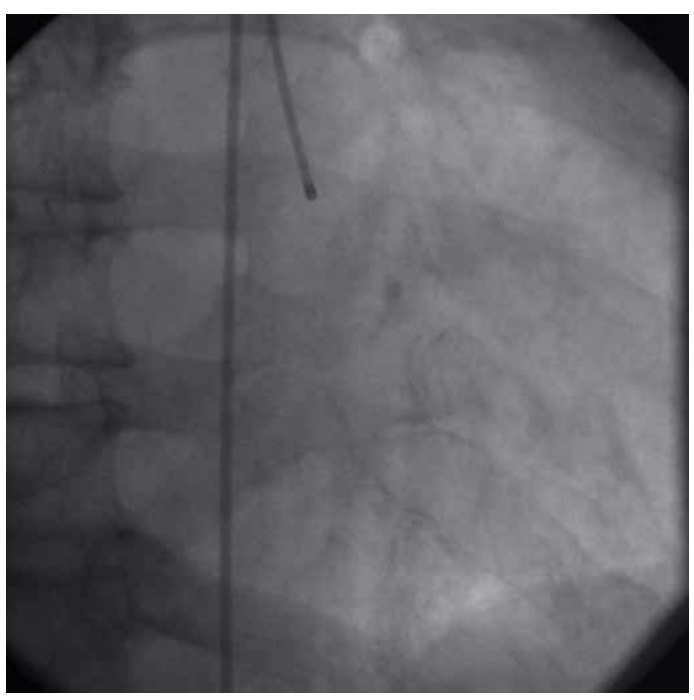

Video 1 Visuals of coronary angiography before acetylcholine provocation.

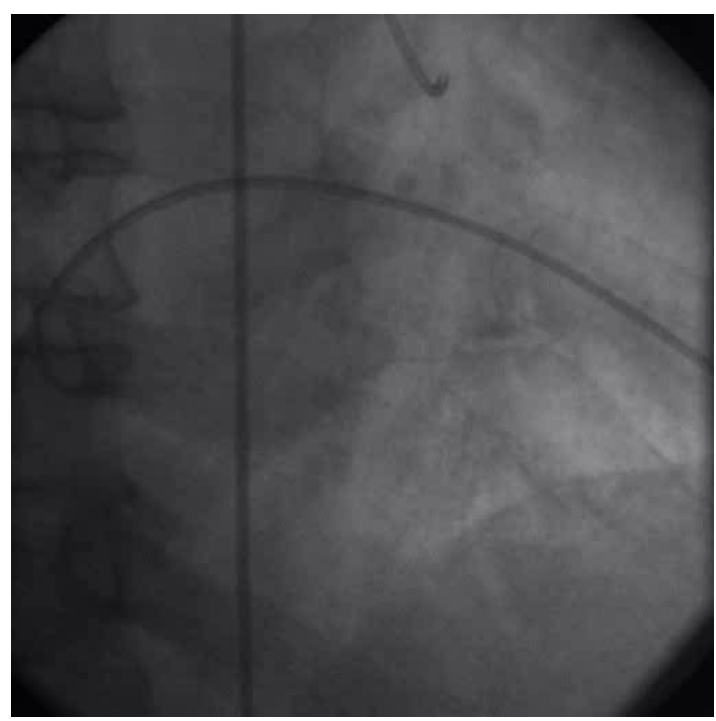

Video 2 Visuals of coronary angiography after acetylcholine provocation.

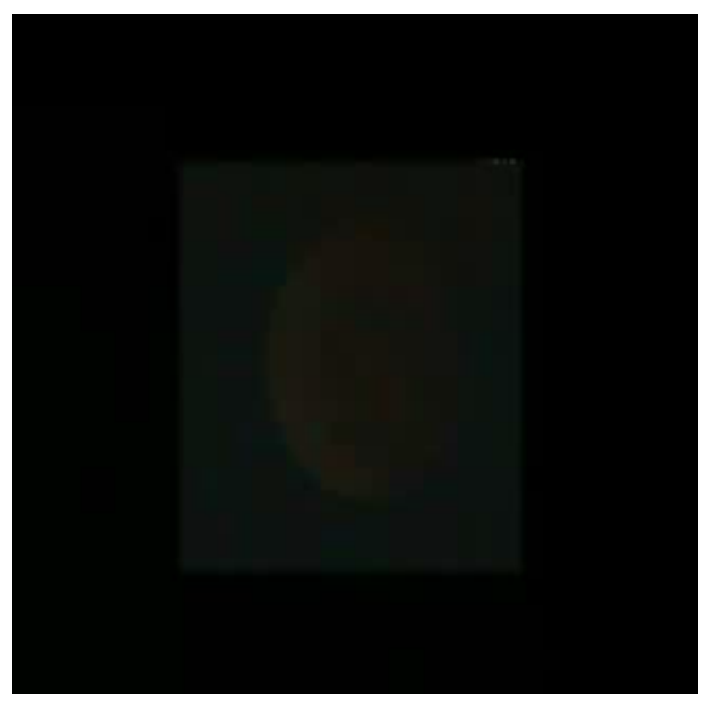

Video 3 Visuals of coronary angioscopy.

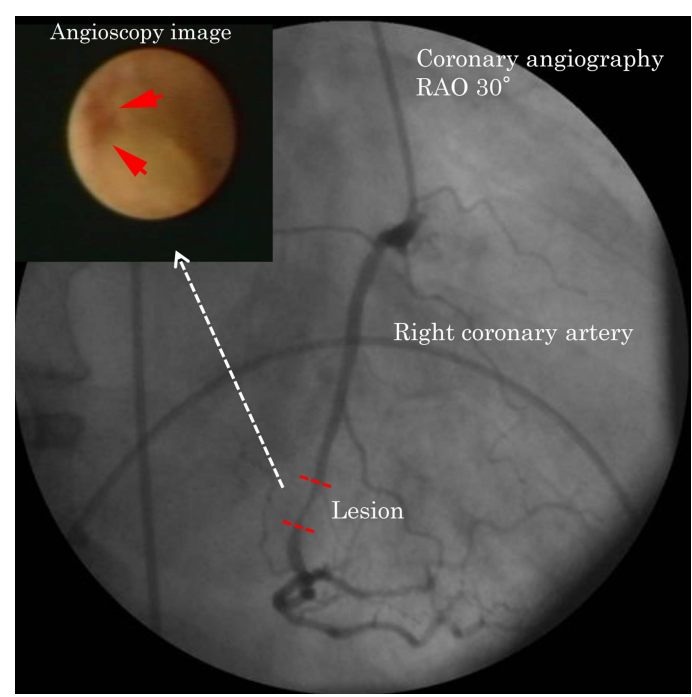

Figure 3 Images from coronary angiography and angioscopy. Angiography showed coronary spasm in segment 2 . An erosion was observed in the lesion by angioscopy (bold red arrows).
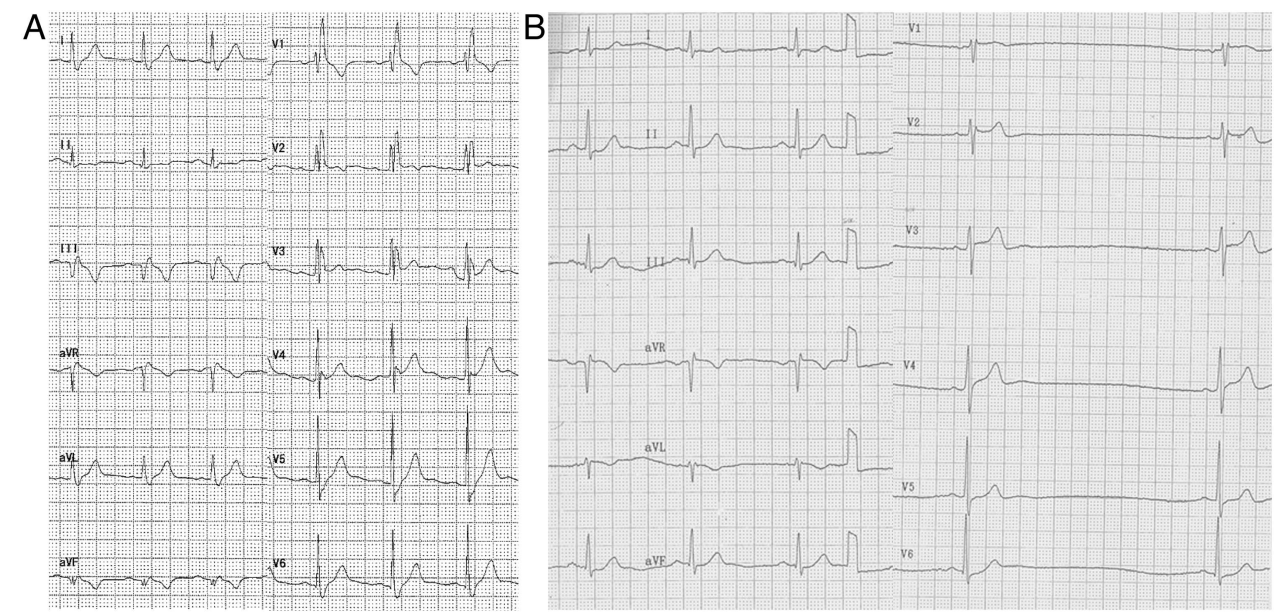

Figure 2 Images from the ECG. (A) Before acetylcholine provocation. (B) After acetylcholine provocation. 


\section{Learning points}

- This is the first case in which intimal injury of a focal spastic lesion has been confirmed by coronary angioscopy in a case of acute coronary syndrome.

- This case indicates that coronary spasm may be associated with acute coronary syndrome.

Contributors SN was involved in the study concept and design, analysis and interpretation of data, collection and assembly of data, drafting of the article and critical revision of the article for important intellectual content. SN takes responsibility for the manuscript as a whole. MK was involved in the study concept and design, analysis and interpretation of data, drafting of the article and critical revision of the article for important intellectual content. HT was involved in the drafting of the article and critical revision of the article for important intellectual content. WS was involved in the study concept and design, drafting of the article, critical revision of the article for important intellectual content and final approval of the article.

Competing interests None declared.

\section{Patient consent Obtained.}

Provenance and peer review Not commissioned; externally peer reviewed.

\section{REFERENCES}

1 Virmani $R$, Burke AP, Farb $A$, et al. Pathology of the vulnerable plaque. J Am Coll Cardiol 2006;47(8 Suppl):C13-18.

2 Nakamura S, Inami S, Murai K, et al. Relationship between cholesterol crystals and culprit lesion characteristics in patients with stable coronary artery disease: an optical coherence tomography study. Clin Res Cardiol 2014;103:1015-21.

3 Nakamura T, Furukawa K, Uchiyama H, et al. Stent placement for recurrent vasospastic angina resistant to medical treatment. Cathet Cardiovasc Diagn 1997:42:440-3.

Copyright 2015 BMJ Publishing Group. All rights reserved. For permission to reuse any of this content visit http://group.bmj.com/group/rights-licensing/permissions.

BMJ Case Report Fellows may re-use this article for personal use and teaching without any further permission.

Become a Fellow of BMJ Case Reports today and you can:

- Submit as many cases as you like

- Enjoy fast sympathetic peer review and rapid publication of accepted articles

- Access all the published articles

- Re-use any of the published material for personal use and teaching without further permission

For information on Institutional Fellowships contact consortiasales@bmjgroup.com

Visit casereports.bmj.com for more articles like this and to become a Fellow 